\title{
Oral Health Status of Mentally Subnormal Sample Saudi Populace-A Cross-sectional Study
}

\author{
1Bayann D Almoghamer, ${ }^{2}$ Nadyah M Alghamdi, ${ }^{3}$ Rafi A Togoo
}

\section{ABSTRACT}

Aim: To assess the oral health status and oral hygiene of mentally subnormal population of Abha, Kingdom of Saudi Arabia.

Materials and methods: A cross-sectional study was conducted among 300 mentally sub-normal people of Abha, Kingdom of Saudi Arabia. All the subjects who were willing to participate and were suffering from mental retardation were included in the study. Those subjects with any other medical ailment such as epilepsy, and those having any physical disability were excluded from the study. All the subjects were examined by the investigator for dental caries experience using dental caries experience using (DMFT) (WHO 1997), type of Angle's molar relation was recorded on a recording proforma for all the study participants. Subjects' plaque score was assessed using Silness P. and Loe H. Plaque Index (1964).

Results: The overall prevalence of dental caries (D) found in the present study was $82.6 \%$. On comparing the mean DMFT scores based on different plaque scores, it was found that the subjects with plaque score as 3 had the highest mean DMFT $(5.5376 \pm 3.02367)$; those subjects with least plaque score (1) had mean DMFT of $3.9677 \pm 2.31862$ while those subjects with no plaque had the least mean DMFT $(1.9375 \pm 2.01506)$. A statistically significant $(p=0.000)$ difference was found between the mean plaque scores when compared on the basis of brushing frequency.

Conclusion: It was concluded that the oral health status of the mentally subnormal study population was poor with increased mean plaque scores indicating the neglect of oral hygiene maintenance and dental care and treatment by the study population.

Clinical significance: Oral health of mentally disabled persons is deteriorated owing to various reasons such as social, economic, behavioral factors, the effect of medicines and also difficulty faced by caregivers in providing oral health care including oral hygiene methods. In order to appropriately explore ways and methods for adequately reducing the disease burden on the populace, dentists essentially need to know the oral health status of disabled section thereof.

Keywords: Mentally sub-normal population, DMFT, Plaque, Oral health.

How to cite this article: Almoghamer BD, Alghamdi NM, Togoo RA. Oral Health Status of Mentally Subnormal Sample Saudi Populace-A Cross-sectional Study. World J Dent 2018;9(5):406-411.

\footnotetext{
${ }^{1-3}$ Department of Orthodontics and Pediatric Dentistry, King Khalid University College of Dentistry, Abha, Kingdom of Saudi Arabia

Corresponding Author: Bayann D Almoghamer, Dental Intern, Department of Orthodontics and Pediatric Dentistry, King Khalid University College of Dentistry, Abha, Kingdom of Saudi Arabia, Mobile: +966538802472, e-mail: bayandq@yahoo.com
}

Source of support: Nil

Conflict of interest: None

\section{INTRODUCTION}

We say a person is mentally ill if and when his/ her behavior, feelings, actions, and thinking are affected to a degree which is in no way normal as seen in people en-masse. ${ }^{1}$ Mental illness may be inflicted on a person irrespective of his/her age, gender, culture or ethnicity. Various conditions causal to mental illness are depression, schizophrenia, bipolar disorder, obsessive-compulsive disorder, panic disorder, post-traumatic stress disorder, personality disorder, eating disorders, and addictive behaviors. ${ }^{1,2}$ According to World Health Organization (WHO), about $25 \%$ of the world's population involving both the developed and developing nations suffer from the ailment. ${ }^{3,4}$ Moreover, mental illness is the major cause of disability across the world. ${ }^{4}$ Various studies covering different age groups have been undertaken in Saudi Arabia to arrive at the underlying causes of the prevalence of mental disorder: one of the studies conducted among high school students pinpointed $48 \%$ of mental illness among the studying youth. ${ }^{5}$

It has been documented as is also seen on the ground by one and all that a person, particularly a child, who is mentally/physically disabled faces social deprivation and rejection which plunges him into an isolated life scenario. $^{6}$

Such sufferers are not akin to utilizing health services properly due to which their general, as well as oral health, worsens day in and day out. Deterioration of oral health of mentally disabled persons is multiplied owing to various reasons such as social, economic, behavioral factors, the effect of medicines and also difficulty faced by caregivers in providing oral health care including oral hygiene methods. ${ }^{7}$ Self-oral-hygiene performance among people with special needs directly correlates to the adverse effect of their considerable motor, sensory and intellectual disabilities. Though theoretically/ideally, the right to get the oral health care is same for all, be it the normal or the disabled persons, but empirically it is not so as invariably seen in different societies.

Of the most prevalent oral diseases, dental caries is the dominant ailment among the mentally retarded population; and it is an irony that dental treatment has 
been found figuring at the top of the list of the unmet health needs in our populace. ${ }^{8}$

As widely reported in the pertinent literature, malocclusion is no exception in oral health disparities between individuals suffering from mental sub-normality and the general population. Overall physical health, oral function, ability to communicate and ultimately the quality of life of an individual is hugely affected by his oral health status. Malocclusion in a person with a mental disability becomes a big additional hurdle to his social acceptance not only from an aesthetic point of view but also as a factor of compromise in various aspects of oral function such as mastication or swallowing patterns. ${ }^{9}$

In order to appropriately explore ways and methods for adequately reducing the disease burden on the populace, dentists essentially need to know the oral health status of disabled section thereof. With this goal in view, a study was undertaken to assess the oral health status and oral hygiene of mentally subnormal strata of the population of Abha region, Kingdom of Saudi Arabia.

\section{MATERIALS AND METHODS}

A cross-sectional study was conducted among 300 mentally sub-normal people of Abha, Kingdom of Saudi Arabia to assess their oral health status and oral hygiene performance. Before the start of the study, ethical approval was taken from Scientific Research Committee, King Khalid University College of Dentistry, Abha. All the subjects who were willing to participate, suffering from mental retardation and of age $\geq 12$ years, were included in the study. Those subjects with any other medical ailment such as epilepsy, and those having any physical disability were excluded from the study. Permission for conducting the study was taken from authorities of the 4 Institutions, in Abha, Kingdom of Saudi Arabia, a few days before the actual day of oral examination. An informed consent was taken from the caregivers of the subjects. A single examiner was trained and calibrated in the department of King Khalid University College of Dentistry for diagnosis of dental caries, malocclusion, and dental plaque by examining 20 patients visiting the hospital outpatient department (OPD). The intra-examiner reliability was assessed using kappa statistics which was found to be satisfactory.

Sufficient sterilized sets of instruments (mouth mirrors, explorers, WHO periodontal probes) were carried to the Institutions of the mentally sub-normal patients. All the subjects were examined by the investigator for dental caries experience using DMFT (WHO 1997), type of Angle's molar relation was recorded on a recording proforma for all the study participants. No radiographs were taken. Also, subjects' plaque score was assessed using Silness -Loe Plaque Index (1964); wherein the scoring of plaque range from 0 to 3 . The caregivers of the subjects were asked about the frequency of tooth brushing of the subjects. Demographic data such as age and gender of subjects were also recorded on a proforma. For ease in recording, an assistant was employed to record the data on a proforma.

\section{Statistical Analysis}

The data was analyzed using Statistical Package for the Social Sciences (SPSS) version 16.0. The descriptive statistics of variables (frequency, percentage, mean \pm SD) were calculated. The significance of means of plaque score and DMFT for two groups was tested by using T-test and for more than two groups one way analysis of variance (ANOVA) was used, followed by multiple comparison tests, i.e., Bonferroni test. The categorical data were tested by Pearson's Chi-square test. The level of significance and confidence interval (CI) were $5 \%$ and $95 \%$ respectively.

\section{RESULTS}

In the present study, out of the total 300 study subjects; 217 (72.3\%) were females and $83(27.7 \%)$ were males. Age of the subjects ranged from 12 years to 61 years. Frequency distribution of participants based on various characteristics is shown in Table 1.

On comparing the mean DMFT scores based on different plaque scores, it was found that the subjects with plaque score as 3 had the highest mean DMFT $(5.5376 \pm 3.02367)$; those subjects with least plaque score (1) had mean DMFT of $3.9677 \pm 2.31862$ while those subjects with no plaque had the least mean DMFT $(1.9375 \pm 2.01506)$. A statistically significant difference was found (Table 2). The overall prevalence of dental caries (D) found in the present study was $82.6 \%$; while missing (M ) teeth constituted $70.66 \%$, and filled $(\mathrm{F})$ teeth constituted $37.3 \%$.

Table1: Frequency distribution of study subjects as per various variables

\begin{tabular}{lll}
\hline Variables & & $N(\%)$ \\
\hline Gender & Male & $83(27.7 \%)$ \\
& Female & $217(72.3 \%)$ \\
\hline Age category & $12-21$ years & $88(29.3 \%)$ \\
& $22-31$ years & $103(34.3 \%)$ \\
& $32-1$ years & $85(28.3 \%)$ \\
& $42-51$ years & $20(6.7 \%)$ \\
\hline Brushing frequency & Nil & $4(1.3 \%)$ \\
& Once & $78(26.0 \%)$ \\
& Twice & $140(46.7 \%)$ \\
\hline Malocclusion & Class I & $82(27.3 \%)$ \\
& Class II (Divl + Div II) $110(36.7 \%)$ \\
& Class III & $73(24.3 \%)$ \\
\hline
\end{tabular}


Comparison of brushing frequency with mean DMFT showed a non-significant difference $(p=0.529)$ while a statistically significant $(\mathrm{p}=0.000)$ difference was found between the mean plaque scores when compared on the basis of brushing frequency (Table 3). Comparison based on age showed that the mean plaque and mean DMFT values increase as the age increases with a statistically significant difference (Table 4).

\section{DISCUSSION}

The poor oral health of disabled population poses a great disease burden in the community. ${ }^{10,11}$ The prevalence of

Table 2: Comparison of DMFT by different plaque scores

\begin{tabular}{|c|c|c|c|c|c|c|}
\hline \multirow[b]{2}{*}{ Plaque scores } & \multirow[b]{2}{*}{$N$} & \multirow[b]{2}{*}{ Mean \pm Std. deviation } & \multicolumn{4}{|c|}{$95 \%$ confidence interval for mean } \\
\hline & & & Lower bound & Upper bound & F-value & $p$-value ${ }^{\wedge}$ \\
\hline 0 & 32 & $1.9375 \pm 2.01506$ & 1.2110 & 2.6640 & & \\
\hline 1 & 62 & $3.9677 \pm 2.31862$ & 3.3789 & 4.5566 & & \\
\hline 2 & 113 & $4.7876 \pm 2.27349$ & 4.3639 & 5.2114 & 17.719 & $0.000^{* *}$ \\
\hline 3 & 93 & $5.5376 \pm 3.02367$ & 4.9149 & 6.1604 & & \\
\hline Total & 300 & $4.5467 \pm 2.71891$ & 4.2377 & 4.8556 & & \\
\hline Plaque score & $\begin{array}{l}\text { Mean } \\
\text { Difference }\end{array}$ & $p$ value ${ }^{\wedge \wedge}$ & Plaque score & Mean difference & $p$-value ${ }^{\wedge \wedge}$ & \\
\hline 0 vs 1 & -.03024 & $0.002^{*}$ & 1 vs 2 & -0.81987 & $0.241 \#$ & \\
\hline 0 vs 2 & -2.85011 & $0.000^{\star *}$ & 1 vs 3 & $-1.56989^{*}$ & $0.001^{*}$ & \\
\hline 0 vs 3 & --3.60013 & $0.000^{* *}$ & 2 vs 3 & -0.75002 & $0.204 \#$ & \\
\hline
\end{tabular}

*-Significant $p<0.05,{ }^{* *}$-Highly significant $p<0.001$, \#-Not significant $p>0.05$

$\wedge$ ^-By one way ANOVA, ${ }^{\wedge}$-by Bonferroni test

Table 3: Comparison of DMFT and plaque scores by the brushing frequency of subjects

\begin{tabular}{|c|c|c|c|c|c|c|c|}
\hline & \multirow{2}{*}{$\begin{array}{l}\text { Brushing } \\
\text { frequency }\end{array}$} & \multirow[b]{2}{*}{$N$} & \multirow[b]{2}{*}{ Mean \pm Std. deviation } & \multicolumn{2}{|c|}{$95 \%$ confidence interval for mean } & \multirow[b]{2}{*}{$F$} & \multirow[b]{2}{*}{$p$-value ${ }^{\wedge}$} \\
\hline & & & & Lower bound & Upper bound & & \\
\hline \multirow[t]{4}{*}{$D M F T$} & Nil & 78 & $4.8462 \pm 3.13786$ & 4.1387 & 5.5536 & \multirow{4}{*}{0.639} & \multirow{4}{*}{ 0.529\# } \\
\hline & Once & 140 & $4.4357 \pm 2.54233$ & 4.0109 & 4.8605 & & \\
\hline & Twice & 82 & $4.4512 \pm 2.59226$ & 3.8816 & 5.0208 & & \\
\hline & Total & 300 & $4.5467 \pm 2.71891$ & 4.2377 & 4.8556 & & \\
\hline \multirow[t]{4}{*}{ Plaque score } & Nil & 78 & $2.36 \pm 0.772$ & 2.18 & 2.53 & 28.395 & $0.000^{* *}$ \\
\hline & Once & 140 & $1.96 \pm 0.955$ & 1.80 & 2.12 & & \\
\hline & Twice & 82 & $1.32 \pm 0.873$ & 1.13 & 1.51 & & \\
\hline & Total & 300 & $1.89 \pm 0.967$ & 1.78 & 2.00 & & \\
\hline $\begin{array}{l}\text { Brushing } \\
\text { frequency }\end{array}$ & $\begin{array}{l}\text { Mean } \\
\text { Difference }\end{array}$ & $p$-value ${ }^{\wedge \wedge}$ & Brushing frequency & $\begin{array}{l}\text { Mean } \\
\text { Difference }\end{array}$ & $p$ value $e^{\wedge \wedge}$ & & \\
\hline Nil vs Once & $.395^{*}$ & $.006^{*}$ & Once vs Twice & $0.647^{*}$ & $0.000^{* *}$ & & \\
\hline Nil vs Twice & $1.042^{*}$ & $.000^{\star *}$ & & & & & \\
\hline
\end{tabular}

*-Significant $p<0.05,{ }^{* *}$-Highly significant $p<0.001$, \#-Not significant $p>0.05$

$\wedge$-By one way ANOVA, ${ }^{\wedge}$-by Bonferroni test

Table 4: Comparison of DMFT and plaque scores by the age of subjects

\begin{tabular}{|c|c|c|c|c|c|c|c|}
\hline & & \multirow[b]{2}{*}{$N$} & \multirow[b]{2}{*}{ Mean \pm Std. deviation } & \multicolumn{2}{|c|}{ 95\% confidence interval for mean } & \multirow[b]{2}{*}{$F$} & \multirow[b]{2}{*}{$p$-value ${ }^{\wedge}$} \\
\hline & & & & Lower bound & Upper bound & & \\
\hline \multirow[t]{6}{*}{ DMFT } & $12-21$ years & 88 & $3.056 \pm 2.080$ & 1.9823 & 2.7844 & \multirow{6}{*}{21.450} & \multirow{6}{*}{$0.000^{\star *}$} \\
\hline & 22--31 years & 103 & $4.3883 \pm 2.501$ & 3.9043 & 4.7984 & & \\
\hline & $32-41$ years & 85 & $5.4118 \pm 2.560$ & 4.8380 & 5.9092 & & \\
\hline & $42-1$ years & 20 & $7.3500 \pm 2.700$ & 4.9497 & 7.1128 & & \\
\hline & $52-61$ years & 4 & $9.000 \pm 1.632$ & 7.3794 & 11.2873 & & \\
\hline & Total & 300 & $4.546 \pm 2.7189$ & 4.2377 & 4.8556 & & \\
\hline \multirow[t]{6}{*}{ Plaque score } & 12-21 years & 88 & $1.50 \pm 0.959$ & 1.09 & 1.55 & \multirow[t]{6}{*}{10.723} & \multirow[t]{6}{*}{$0.000^{* *}$} \\
\hline & 22-31 years & 103 & $1.80 \pm 0.964$ & 1.50 & 1.86 & & \\
\hline & $32-1$ years & 85 & $2.21 \pm 0.832$ & 2.07 & 2.41 & & \\
\hline & $42-51$ years & 20 & $2.50 \pm 0.761$ & 2.23 & 2.77 & & \\
\hline & 52-61 years & 4 & $3.00 \pm 0.000$ & 3.00 & 3.00 & & \\
\hline & Total & 300 & $1.89 \pm 0.967$ & 1.78 & 2.00 & & \\
\hline
\end{tabular}

${ }^{\wedge}$ By one way ANOVA

** Highly significant 
oral diseases is much better in the general population than seen in mentally sub-normal people. ${ }^{12}$ Hence, a study was carried out to explore the hidden burden of disease among the mentally sub-normal population in Abha, Kingdom of Saudi Arabia.

A commonly used tool used to evaluate the dental caries experience is the DMFT index ( $\mathrm{D}=$ decayed, $\mathrm{M}=$ missing, $\mathrm{F}=$ filled, $\mathrm{T}=$ teeth). ${ }^{13} \mathrm{DMFT}$ index was given by Klein et al., ${ }^{14}$ in 1938 as a tool for cumulative caries measure indicating both past as well as present dental caries experience. This index provides the dental caries status which is quite important for the planning of preventive and curative measures by public health policymakers. ${ }^{15}$

World Health Organization (WHO), formulated a scale to indicate the level of severity of dental caries based on DMFT scores. DMFT scores ranging between 0.0 and 1.1 were categorized as very low; 1.2 to 2.6 as low; 2.7 to 4.4 as moderate, 4.5 to 6.5 as high, and values more than 6.6 as very high. ${ }^{13}$

The results of the present study showed that the overall mean DMFT of the study subjects was found to be $4.5467 \pm 2.71891$. The high mean DMFT value was observed in the previous study wherein Shyama et.al. ${ }^{16}$ reported a mean DMFT of 4.5 for the disabled population. In a yet another $\mathrm{p}$ study done on mentally challenged individuals, the researchers found a DMFT of 3.08 which was higher than that found in individuals with other disabilities. ${ }^{17}$ It is mentioned in the previous study that dental caries is the most common oral health problem faced by mentally disabled children being one of the most neglected health needs. ${ }^{18}$ The reasons might be less cooperation shown by patients, difficulties faced during treatment procedures, communication gap, ${ }^{8}$ limited understanding of the need for treatment, ${ }^{18}$ a fear of dental treatment. ${ }^{19}$ The poor oral health of adults with disabilities might be attributed to under-diagnosis and differential oral health treatment. ${ }^{20,21}$

One of the most important factors regarding high dental caries prevalence among the subjects of the present study is poor oral hygiene performance. In previous studies, poor oral hygiene has been documented as the main factor in causing dental caries as well as periodontal diseases among mentally sub-normal people. ${ }^{22,23}$

The results of the present study showed that those study subjects who did not brush their teeth had the highest plaque mean scores of $2.36 \pm 0.772$ while those who brushed their teeth twice had the least mean plaque score of $1.32 \pm 0.873$. The difference was found to be statistically significant. These results are indicative of the fact that plaque accumulation is associated with brushing frequency. It is mentioned in the previous study that efficient tooth brushing is quite important for good oral hygiene. ${ }^{24}$ In a study carried out in Riyadh, poor oral hygiene was found among young mentally retarded female children. Lack of understanding about the importance of maintaining oral hygiene might be the reasons for their poor oral hygiene, ${ }^{25}$ hence motivation and re-enforcement through education programs is most imperative for the disabled population. ${ }^{26}$

In the present study, malocclusion was assessed based on Edward Angle (1899) classification of malocclusion who classified it as class I, class II (division 1 and division 2) and class III. ${ }^{27}$ Our study results showed that 39\% of subjects had class I malocclusion followed by class II $(36.7 \%)$ and class III (24.3\%) malocclusion. These findings were in accordance to previous study wherein majority of the subnormal study population had class I malocclusion followed by class II and class III. ${ }^{28}$ Malocclusion is also one of the factors for increased prevalence of dental caries among the mentally sub-normal population. Moreover, malocclusion has a direct impact on the aesthetic appearance and hence causes lowering of self-confidence among mentally sub-normal people who eventually resist themselves from social participation; other than personal problems of mastication and swallowing patterns.

The results of the present study indicated that the mean DMFT scores of study population increase with advancing age. Similar results were found in the previous study conducted on psychiatric inpatients in Rennes, France; wherein the logistic regression analysis showed age as a potential contributing factor for high DMFT. ${ }^{29}$

The overall oral health status of subjects of the present study was quite deteriorated hence call for a considerate attention towards such group of the population so that the health scenario is uplifted in perspective of their better oral as well as general health.

\section{CONCLUSION}

It was concluded that the oral health status of mentally subnormal study population was poor with increased prevalence of dental caries (82.6\%) and increased mean plaque scores indicating the neglect of oral hygiene maintenance and dental care and treatment by them.

\section{Recommendations}

- Creating awareness regarding the importance of preventive and curative services for oral health maintenance is the need of the hour for the disabled population especially the mentally sub-normal group. A collaborative effort should be taken by health care providers, public health dentists, dental specialists of all fields, governing bodies, and authorities of special care institutions and non-governmental organisation (NGOs) to promote oral health among the mentally sub-normal population through organizing targeted 
oral health education programs directed mainly towards caregivers of such people.

- The access and utilization of oral health services should be facilitated for the mentally sub-normal population so that the oral disease burden is reduced by their treatment at an early stage of the disease.

- Teaching the proper ways of tooth brushing through tooth-brushing programs should be carried out for both the caretakers as well as the sub-normal people involving education, motivation, and re-enforcements to have the beneficial long-term effects for them.

- The dentists should not avoid the treatment of mentally disabled people; instead, they should try to fix their appointments at different timings from that of routine normal patients; as more care and time is needed to manage such patients.

- Powered triple headed toothbrushes should be recommended for mentally handicapped people with lesser motor skills.

- Periodic oral health examinations should be carried out for a mentally sub-normal population to detect the oral health issues at their early stages and hence prevent the consequences from the progression of such diseases.

- Use of pit and fissure sealants, fluoride applications and dietary counseling can be as beneficial for mentally disabled children as in normal ones.

- Dentists should be trained through Continued Dental Education Programs regarding various ways of dealing with mentally disabled patients so to reduce the barriers for utilizing the health services by such patients.

\section{Strength of the Study}

The study is the first of its kind that has been carried out on the mentally subnormal section of the population in Southern Saudi Arabia.

\section{Limitation of the Study}

The dietary pattern of the subjects was not assessed. The future studies should include dietary habits so as to relate it to the oral health status of mentally subnormal people.

\section{REFERENCES}

1. Duckworth K. Mental Illness: What you Need to Know. Arlington VA: National Alliance on Mental Illness; 2013.

2. Doran CM. Prescribing Mental Health Medication: The Practitioner's Guide. New York, NY: Routledge; 2005.

3. World Health Organization. WHO Mental Health Gap Action Programme (mhGAP). Geneva: World Health Organization; 2013.

4. World Health Organization. Mental Health Atlas 2011. Geneva: World Health Organization; 2011:82.
5. Al-Sughayr AM, Ferwana MS. Prevalence of mental disorders among high school students in National Guard Housing, Riyadh, Saudi Arabia. J Fam Community Med. 2012 Jan; 19(1): 47-51.

6. Park K. Park's textbook of preventive and social medicine. 19th edn. Jabalpur: Banarasi Das Bhanot Publishers, 2007.

7. United Nations Children's Fund. Children and disability in transition in CEE/CIS and Baltic States. Florence, 2005.

8. Hennequin M, Faulks D, Roux D. Accuracy of estimation of dental treatment need in special care patients. J Dent. 2000 Feb; 28(2):131-136

9. Becker A, Shapira J. Orthodontics for the handicapped child. Europeon Journal of Orthodontics 1996 Jan;18(1):55-67.

10. FFaulks D, Hennequin M. Evaluation of a long-term oral health program by carers of children and adults with intellectual disabilities. Spec Care Dentist 2000 Sep-Oct;20(5): 119-208.

11. Jurek GH, Reid WH. Oral health of institutionalized individu $\neg$ als with mental retardation. Am J Ment Retard 1994 Mar;98(5):656-660.

12. Beange $H$. Caring for a vulnerable population: Who will take responsibility for those getting a raw deal from the health care system? Med J Aust 1996;164:159-160.

13. World Health Organization, 2000. Global Data on Dental Caries Prevalence (DMFT) in Children Aged 12 years. Global Oral Data Bank. Oral health country/area profile programme, Management of noncommunicable diseases. Geneva, May $2000 \mathrm{WHO} / \mathrm{NMH} / \mathrm{MNC} / \mathrm{ORH} /$ Caries.12y.00.3.

14. Klein H, Palmer CE, Knutson JW. Studies on dental caries: I. Dental status and dental needs of elementary school children. Public Health Reports (1896-1970). 1938 May 13:751-765.

15. Jakobsen JR, Hunt RJ. Validation of oral status indicators. Community Dental Health. 1990 Sep;7(3):279-284.

16. Shyama M, Al-Mutawa SA, Morris RE, Sugathan T, Honkala E. Dental caries experience of disabled children and young adults in Kuwait. Community Dent Health 2001 Sep;18(3): 181-186.

17. Shukla D, Bablani D, Chowdhry A, Jafri Z, Ahmad N, et al. Oral Health Status and Dental Caries Experience in Mentally Challenged Individuals. Ann Public Health Res 2014 Oct; 1(2): 1008.

18. Lindemann R, Zaschel-Grob D, Opp S, Lewis MA, Lewis C. Oral health status of adults from a California regional center for developmental disabilities. Spec Care Dentist 2001;21(1): 9-14.

19. Gordon SM, Dionne RA, Snyder J. Dental fear and anxiety as a barrier to accessing oral health care among patients with special health care needs. Spec Care Dentist 1998 Mar-Apr; 18(2):88-92.

20. Cumella S, Ransford N, Lyons J, Burnham H. Needs for oral care among people with intellectual disability not in contact with Community Dental Services. J Intellect Disabil Res 2000 Feb;44:45-52.

21. Reichard A, Turnbull HR, Turnbull AP. Perspectives of dentists, families, and case managers on dental care for individuals with developmental disabilities in Kansas. Ment Retard 2001 Aug;39(4):268-285.

22. Franks AS, Winter GB. Management of the handicapped and chronic sick patient in the dental practice. Br Dent J 1974 Feb 19; 136(4):145-150.

23. Organization WH. Oral health surveys: basic methods. World Health Organization; 1971. 
24. Shaw MJ, Shaw L. The effectiveness of different dental health education programs in improving the oral health of adults with mental handicaps attending Biminghham training centres. Community Dent Health 1991;8:139-145.

25. Al-QahtaniZ,Wyne AH.Caries experience and oral hygiene status of blind, deaf and mentally retarded female children in Riyadh, Saudi Arabia. Odontostomatol Trop 2004 Mar;27(105):37-40.

26. Price JH. The dental health education for the mentally and physically handicapped. J Sch Health 1978 Mar;48(3):171-174.
27. Angle EH. Classification of malocclusion. Dental Cosmos. 1899 Mar;41(3):248-264.

28. Vittek J, Winik S, Winik A, Sioris C, Tarangelo AM, Chou M. Analysis of orthodontic anomalies in Mentally Retarded Developmentally Disabled (MRDD) persons. Special Care in Dentistry 1994 Sep-Oct;14(5):198-202.

29. Jain M,Mathur A,Sawla L,ChoudharyG,KabraK,DuraiswamyP, Kulkarni S. Oral health status of mentally disabled subjects in India. Journal of oral science. 2009;51(3):333-340. 